\title{
Simple Working Key for the Classification and Identification of Named Taxa Included in the International Streptomyces Project $^{1,2}$
}

\author{
EBERHARD KÜSTER \\ Institut für Landwirtschaftliche Mikrobiologie, Justus Liebig-Universität, Giessen, \\ Germany
}

A simple diagnostic key, consisting of 13 tables, for the classification and identification of 274 named taxa included in the International Streptomyces Project (ISP) is presented. By means of the few criteria used in the ISP studies it is possible to identify organisms belonging to most of the named species included in that study. In a few cases, additional characters are required.

Participants in the International Streptomyces Project (ISP) examined 300 strains (many of them type strains) of named Streptomyces species by standardized methods. The results of this cooperative work, i.e., the descriptions, have been published in three papers (7-9). The characters chosen and used in that work (6) are as follows: morphology of sporophores, morphology of spores, color of aerial mycelium, color of the reverse side of the vegetative given in these descriptions be used for classification purposes and for the identification of new isolates and previously unidentified strains in terms of the names included in the ISP studies? The first attempt to use the ISP descriptions for this purpose was undertaken by Arai and Mikami (1), who compiled the information resulting from the ISP study into an identification key for those streptomycetes which produce antifungal antibiotics. It is the intention

TABLE 1. Streptomyces species with white aerial mycelium and distinctive reverse pigment

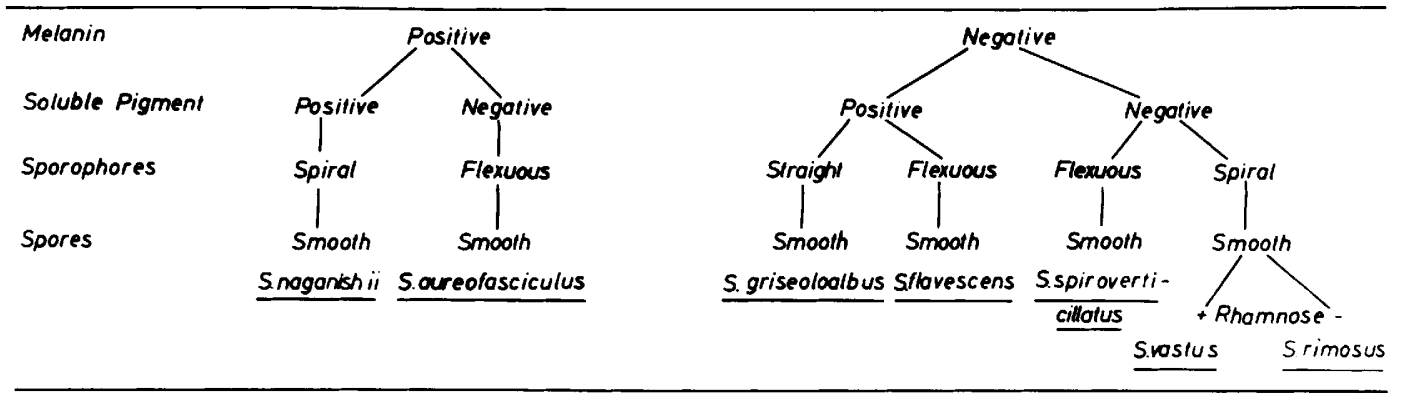

mycelium, melanin reaction, production of soluble pigment, and utilization of nine different sugars. These characteristics were assessed as reliable and constant, based on an analysis of a previous international cooperative study (2). Now the question arises: Can the information

\footnotetext{
'Presented at the "Round Table Conference on Streptomyces," X Int. Congress for Microbiology, Mexico City, August, 1970.

${ }^{2}$ The International Streptomyces Project (ISP) is sponsored by the International Subcommittee on Taxonomy of the Actinomycetes (D. Gottlieb, Chairman).
}

here to produce a key useful for the classification and identification of nearly all of the named species included in the ISP studies.

For classification and identification purposes, dichotomous keys appear to be the most workable. In choosing sequences of characters, it is the author's opinion that the same sequences should be used for each main subdivision where possible and that those characters which are easiest to determine should be used first, followed by those which are more difficult to determine. This is not intended to imply that one character has more 


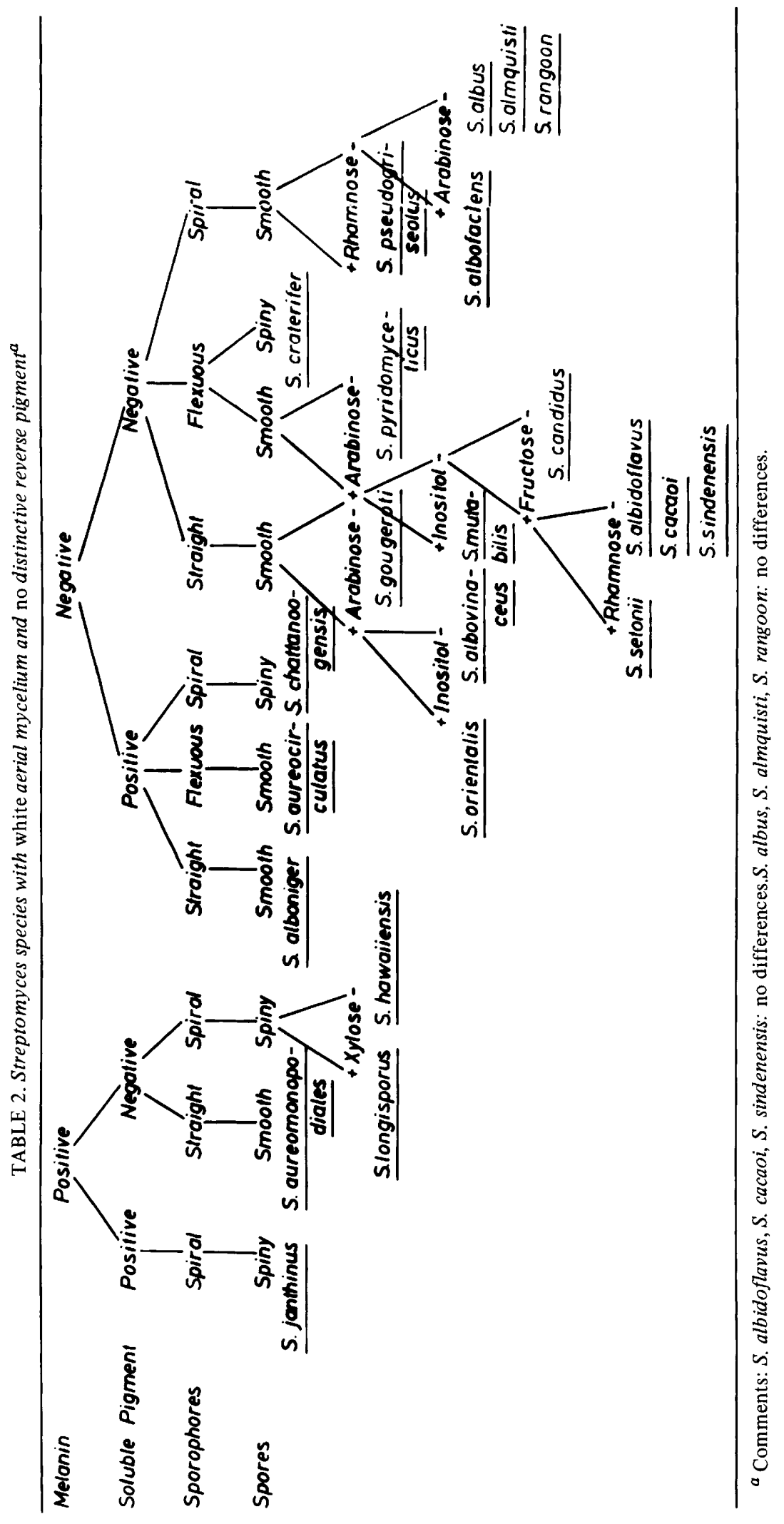




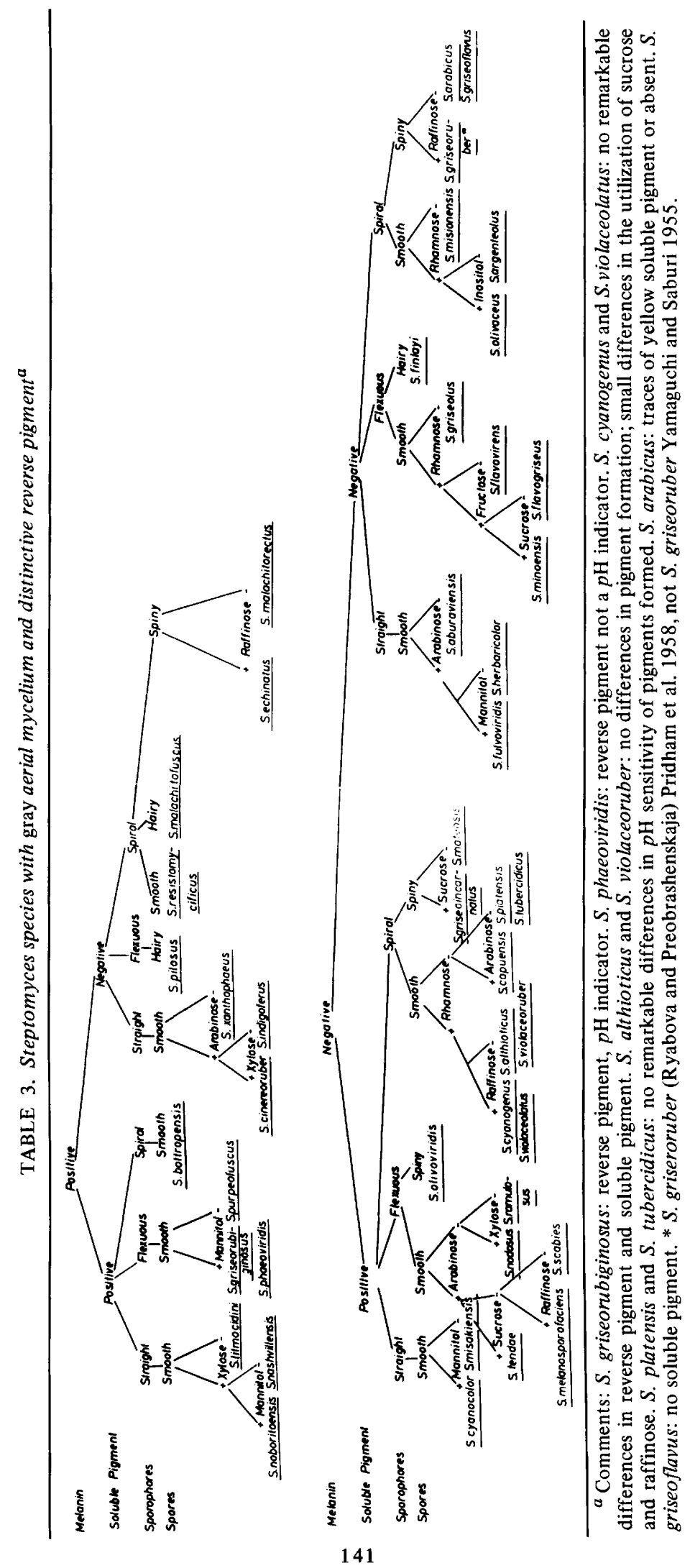



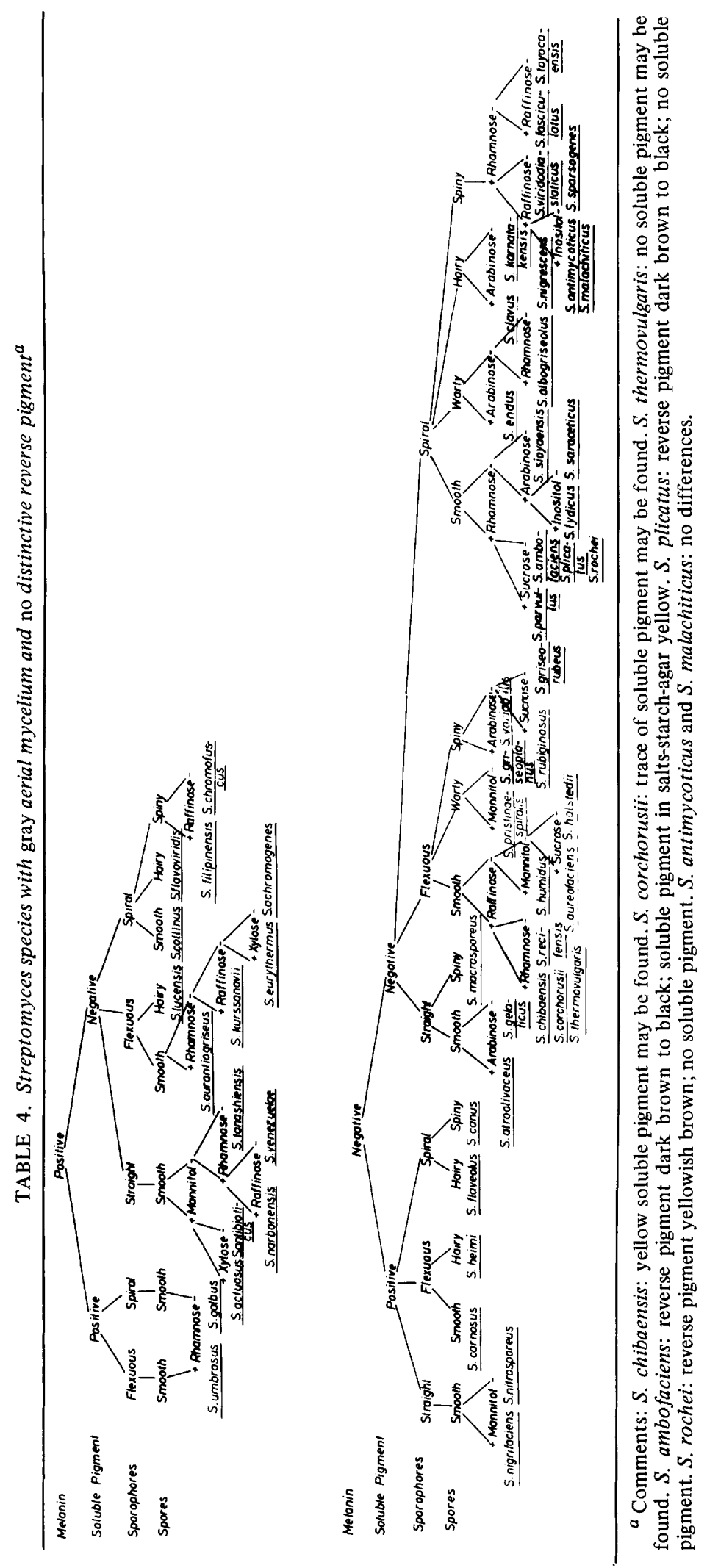
TABLE 5. Streptomyces species with yellow aerial mycelium and distinctive reverse pigment ${ }^{a}$

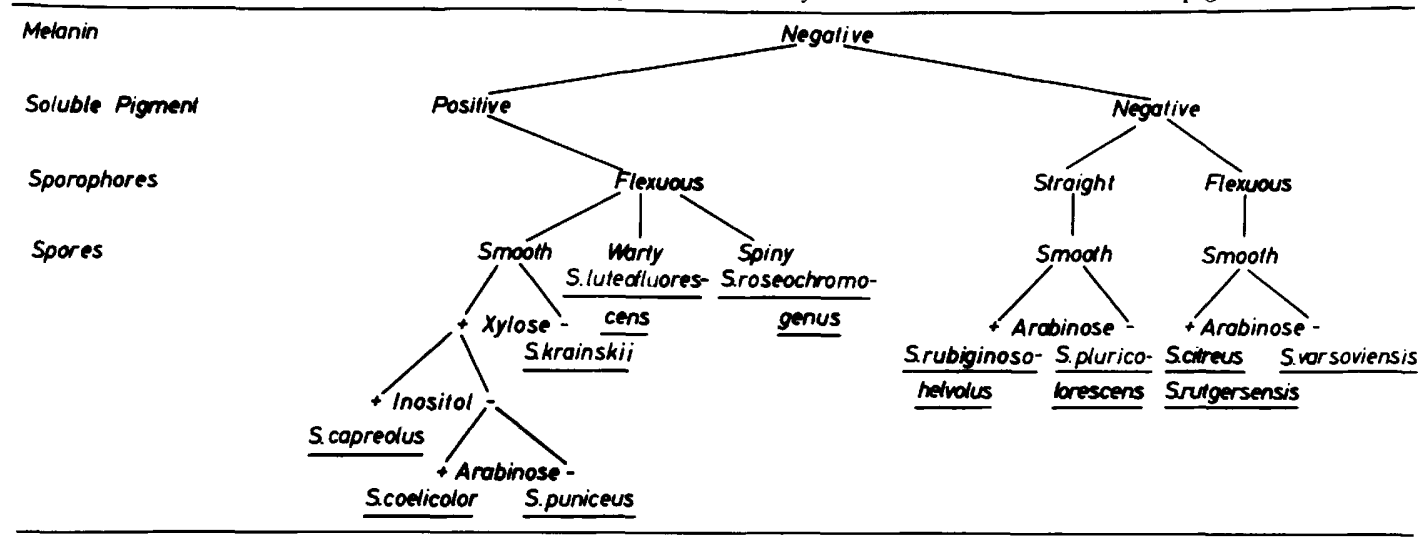

${ }^{a}$ Comment: $S$. citreus and $S$. rutgersensis: no differences.

taxonomic value than another. The author proposed (3) such a simple scheme for grouping streptomycetes and later (4) applied it to a group of streptomycetes which form a green, nondiffusible pigment. The present scheme, which is purely a working one, has the advantage of requiring only two media: oatmeal-agar for the morphology and color determinations and peptone-yeast extractiron-agar for the melanin reaction.

Because of the criteria used and the information given in the ISP description (7-9), the scheme presented herein is a slightly modified version of the original one by the author (3). Because of the great number of named and described strains, initial groupings were made on the basis of the color of the aerial mycelium as follows: white, gray, yellow, red, blue, green. These were then subdivided into two groups: those with and those without a distinctive reverse pigment. Other characters were then used in the following sequence: melanin reaction, formation of a soluble pigment, morphology of sporophores, morphology of spores. As needed, further subdivision was made by using the results of utilization of one or more carbohydrates. Tables 1 to 12 present the keys for each of the groups established on the basis of the presence and color of the aerial mycelium and on the presence or absence of reverse color. Note that more than one species name may be listed in some of the final categories. These multiple listings suggest that additional tests are necessary for further separation, that small differences in the pigments produced appear, or that the names are synonymous. Further differentiation of these similar but differently named organisms was made where possible (see comments to the respective tables). The reverse color of the vegetative mycelium and the diffusible pigment produced are not included in the keys but are mentioned in the comments to the tables if they are helpful in differentiating species.

The observations on morphology and on all of the colors listed in the keys were made from oatmeal-agar cultures, which rarely differed from those produced on other media. Oatmealagar proved good and was consequently used as a standard medium in our laboratory for many years.

An advantage of the scheme presented here over other keys commonly used is that one can note at a glance all of the named strains showing major similarities and differing only in characters subject to differences in interpretation (e.g., straight versus flexuous sporophores). This key also facilitates the selection of a few named strains, mostly type strains, with which new isolates may be compared; it is not necessary to examine the descriptions of all 300 named strains reported in the ISP studies. Also, it is flexible in that newly described species can easily be included.

From the tables it is quite obvious that the relatively few characters determined for each organism included in the ISP studies are sufficient to identify and classify a new isolate. Any additional character which is useful for the description of a named species or even only for one particular strain should be recorded in order to complete the information on its physiological properties and ecological peculiarities.

A special table (no. 13) was devised for strains which lack aerial mycelium and which therefore do not fit into one of the other tables. 

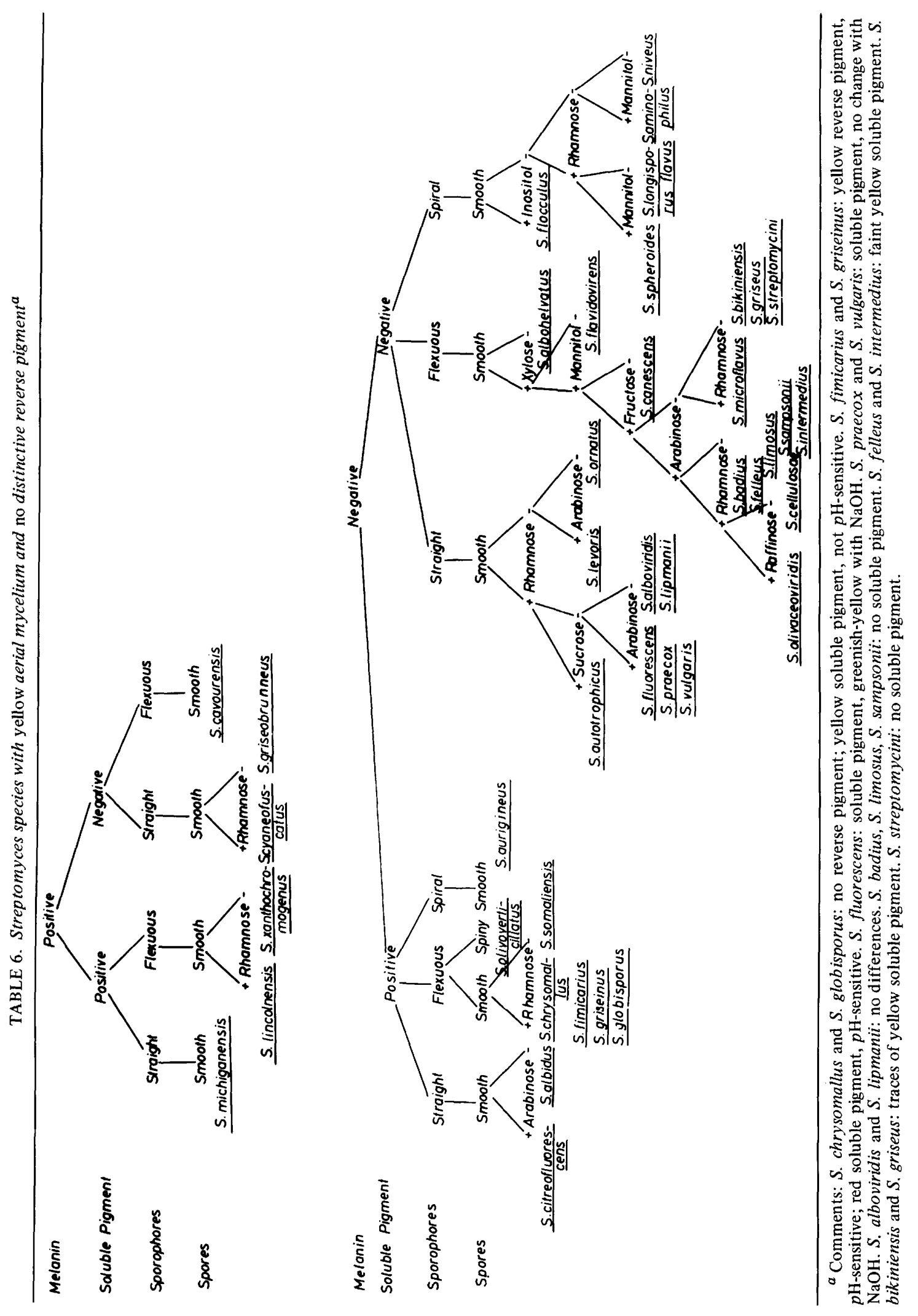
TABLE 7. Streptomyces species with red aerial mycelium and distinctive reverse pigment ${ }^{a}$

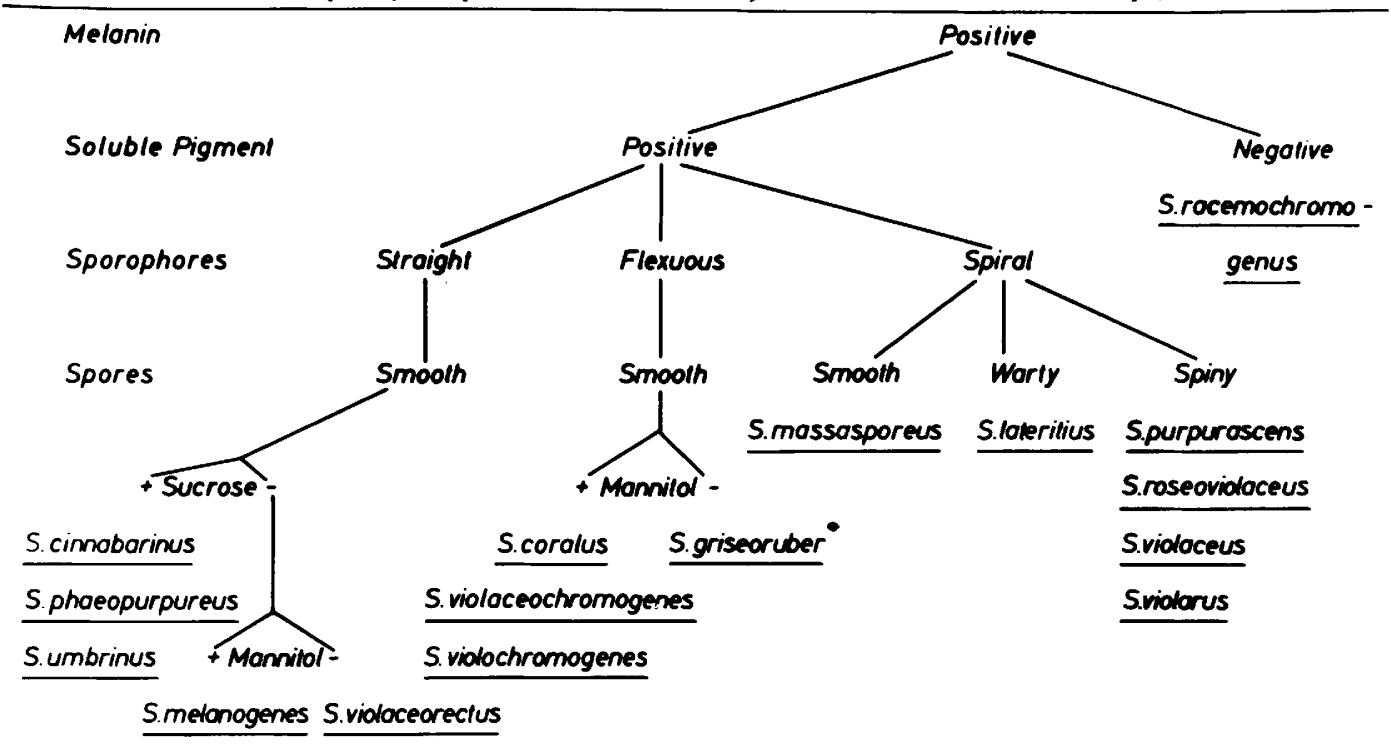

Melanin
Soluble Pigment
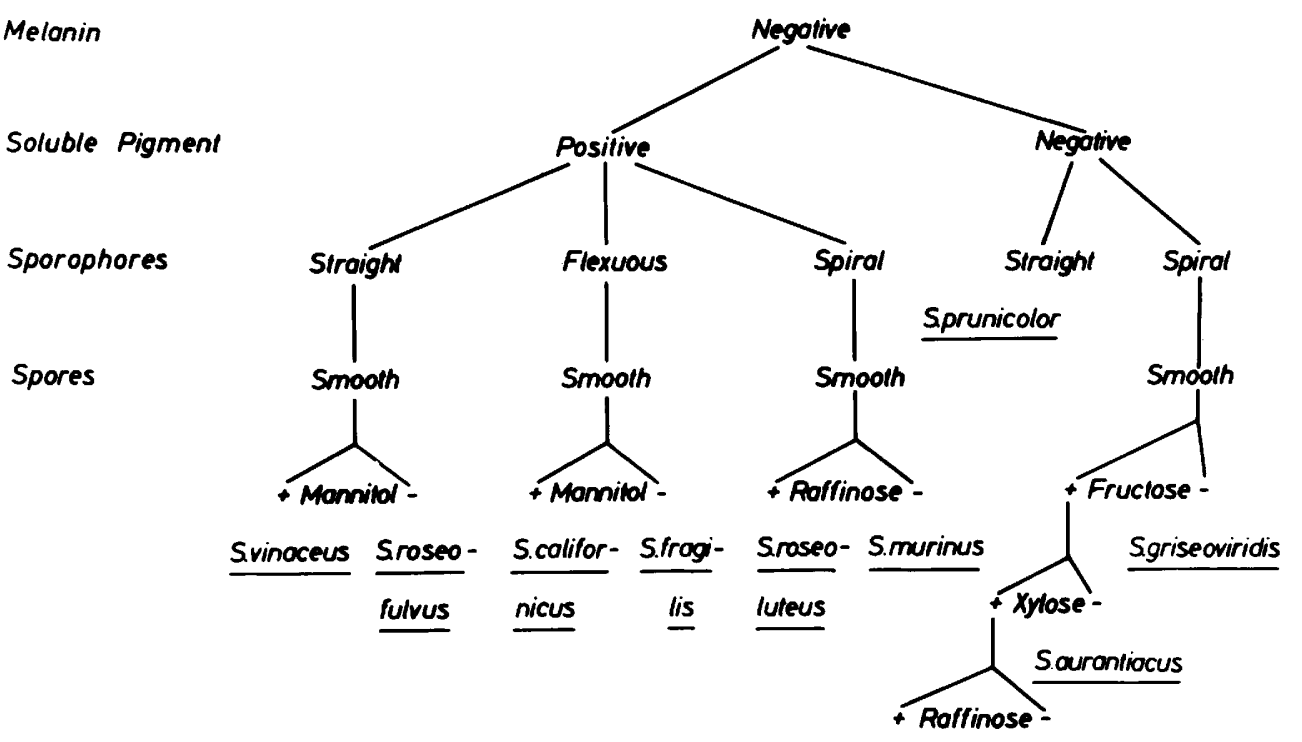

Sfumonus S.doghestonicus

${ }^{a}$ Comments: $S$. cinnabarinus and $S$. phaeopurpureus: red soluble pigment. $S$. umbrinus: yellow soluble pigment. $S$. violachromogenes: yellow soluble pigment, slightly $p \mathrm{H}$-sensitive; reverse pigment $+\mathrm{NaOH}$, no change. $S$. violaceochromogenes: yellow soluble pigment, not $p \mathrm{H}$-sensitive; reverse pigment $+\mathrm{NaOH}$, change from red to violet. $S$. coralus: red soluble pigment, $p \mathrm{H}$-sensitive; reverse pigment $+\mathrm{NaOH}$, change from yellow to red. $S$. purpurascens, $S$. roseoviolaceus, $S$. violaceus, $S$. violarus: no differences. ${ }^{*} S$. griseoruber Yamaguchi and Saburi 1955, not $S$. griseoruber (Ryabova and Priobrashenskaja) Pridham et al. 1958. 
TABLE 8. Streptomyces species with red aerial mycelium and no distinctive reverse pigment ${ }^{a}$

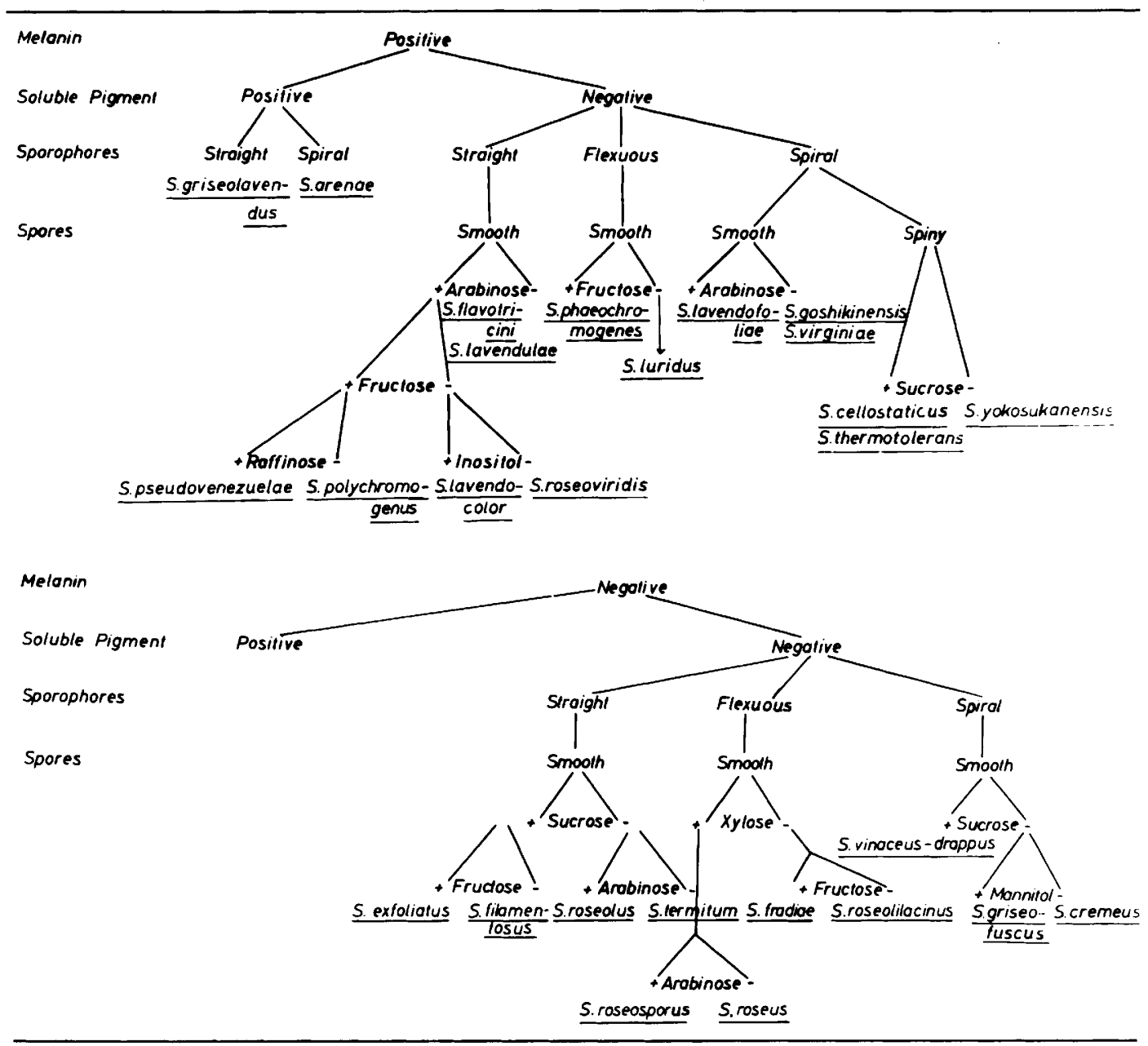

${ }^{a}$ Comments: $S$. flavotricini and $S$. lavendulae: no differences. $S$. goshikinensis: traces of faint yellow soluble pigment. $S$. virginiae: no soluble pigment. $S$. cellostaticus and $S$. thermotolerans: no differences. 
TABLE 9. Streptomyces species with blue aerial mycelium and distinctive reverse pigment ${ }^{a}$

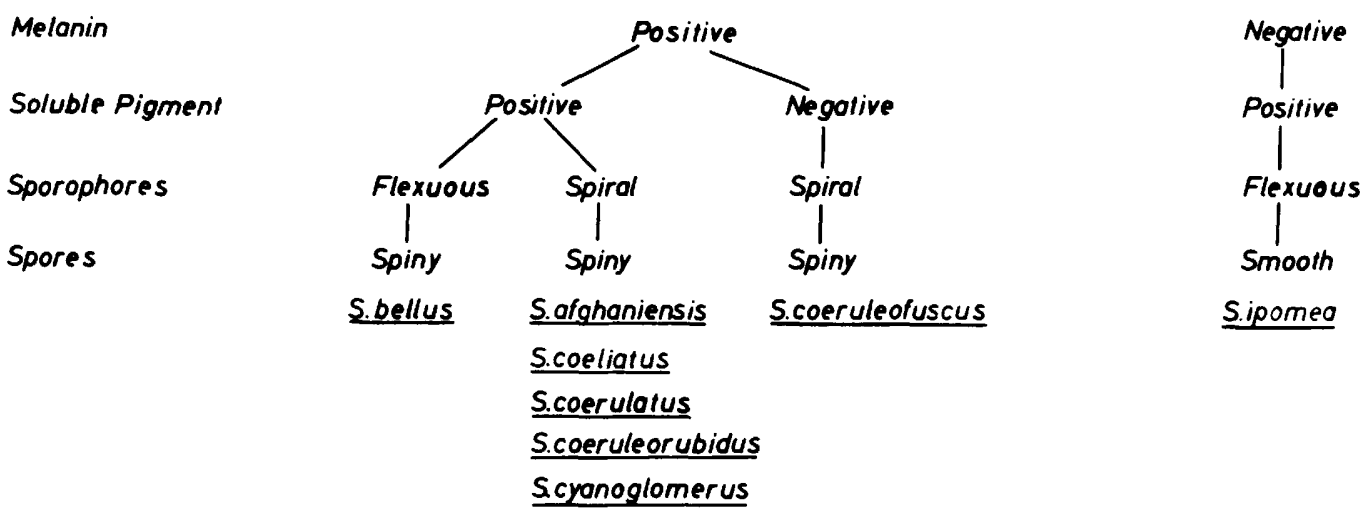

${ }^{a}$ Comments: $S$. afghaniensis and $S$. coeruleorubidus: yellowish reverse pigment and red soluble pigment, neither pigment $p \mathrm{H}$-sensitive. $S$. coeliatus and $S$. cyanoglomerus: dark blue reverse pigment and blue soluble pigment, both $p \mathrm{H}$-sensitive. $S$. coerulatus: grayish blue reverse pigment and blue soluble pigment.

TABLE 10. Streptomyces species with blue aerial mycelium and no distinctive reverse pigment ${ }^{a}$

\section{Melonin}

Soluble Pigment

Sporophores

Spores

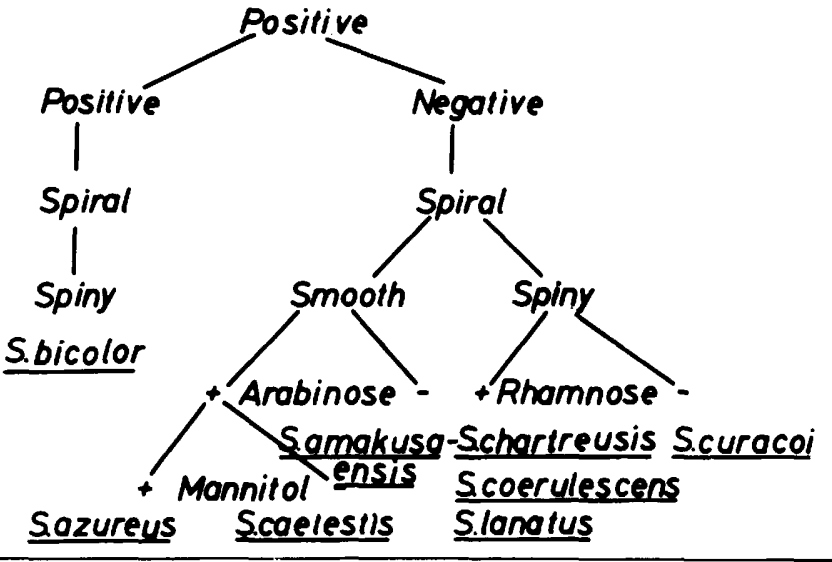

${ }^{a}$ Comments: $S$. chartreusis and $S$. coerulescens: no soluble pigment. $S$. lanatus: traces of yellowish soluble pigment.

TABLE 11. Streptomyces species with green aerial mycelium and distinctive reverse pigment

Solanin

S.griseomycini S.gloucescens 
TABLE 12. Streptomyces species with green aerial mycelium and no distinctive reverse pigment

Melonin

TABLE 13. Streptomyces species without aerial mycelium

Reverse Pigment

Species which possess verticillate sporophores and which were part of the ISP study are not included in the key presented herein. These organisms are considered to belong to the genus Streptoverticillium (5), the species of which have as yet not been examined and described in a standardized manner similar to that used by the ISP for the streptomycetes. The methods of examination and description used in the ISP study were not exactly the same as those applied by Locci et al. to the streptoverticillia (5), and consequently the data are not comparable.

\section{LITERATURE CITED}

1. Arai, T., and Y. Mikami. 1969. Identification keys for antibiotics producing Streptomyces. I. Antifungal antibiotics producers. Annu. Rep. Inst. Food Microbiol. Chiba Univ. 22:59-79.

2. Küster, E. 1961. Results of a comparative study of criteria used in the classification of the Actino- mycetes. Int. Bull. Bacteriol. Nomen. Taxon. 11:91-98.

3. Küster, E. 1967. Problems in the taxonomy of Streptomycetes. Proc. Biochem. 2:20-24.

4. Küster, E. 1970. Note on the taxonomy and ecology of Streptomyces malachiticus and related species. Int. J. Syst. Bacteriol. 20:25-29.

5. Locci, R., E. Baldacci, and B. Petrolini Baldan. 1969. The genus Streptoverticillium. A taxonomic study. G. Microbiol. 17:1-60.

6. Shirling, E. B., and D. Gottlieb. 1966. Methods for characterization of Streptomyces species. Int. J. Syst. Bacteriol. 16:313-340.

7. Shirling, E. B., and D. Gottlieb. 1968. Cooperative description of type cultures of Streptomyces. II. Species descriptions from first study. Int. J. Syst. Bacteriol. 18:69-1 89.

8. Shirling, E. B., and D. Gottlieb. 1968. Cooperative description of type cultures of Streptomyces. III. Additional species descriptions from first and second studies. Int. J. Syst. Bacteriol. 18:279-392.

9. Shirling, E. B., and D. Gottlieb. 1969. Cooperative description of type cultures of Streptomyces. IV. Species descriptions from the second, third, and fourth studies. Int. J. Syst. Bacteriol. 19:391-512. 